\title{
Fenologia, produtividade e qualidade de frutos de jabuticabeiras de diferentes idades das plantas
}

\author{
Leandra Regina Semensato' (1), Eduardo Pradi Vendruscolo2,* (iD, Alexsander Seleguini ${ }^{3}$ (i), \\ Paulo Antônio Batista Filho' ${ }^{\mathbb{D}}$, Eloá Caroline Miranda da Silva' ${ }^{1}$, Thiago Pereira da Silva' ${ }^{1}$
'UNIGOIAS, Centro Universitário de Goiás, Av. João Candido de Oliveira, 115, Cidade Jardim, CEP: 74423-115, Goiânia, GO, Brasil. 2Universidade Estadual de Mato Grosso do Sul, Rod. MS 306, km 6,4, CEP: 79540-000, Cassilândia, MS, Brasil. "Autor para correspondência: agrovendruscolo@gmail.com
${ }^{3}$ Universidade Federal do Triângulo Mineiro, Av. Rio Paranaíba, 1229, Centro, CEP: 38280-000, Iturama, MG, Brasil.

Recebido em 06.VI.2019

Aceito em 20.IV.2020

DOI 10.21826/2446-82312020v75e2020013

\begin{abstract}
RESUMO - Apesar do aumento da demanda por frutos nativos, pouco tem sido explorado quando ao comportamento das espécies nas principais regiões produtoras. Assim, o presente estudo teve como objetivo descrever a fenologia, a produtividade e a qualidade de frutos oriundos de jabuticabeiras de 18 e 32 anos, propagadas por semente, no município de Hidrolândia, Goiás, principal região produtora do fruto na região Centro-Oeste. Verificou-se que o desenvolvimento vegetativo da jabuticabeira ocorre no período de novembro a agosto. O reprodutivo, desde que irrigado, de setembro a outubro, variou de 29 a 46 dias, sendo influenciado pela idade da planta e por fatores climáticos. Em relação às fenofases reprodutivas e a produtividade da jabuticabeira, as plantas apresentam períodos de reprodução, produtividade, tamanho de frutos e rendimento de polpa variáveis. Quanto aos fatores que determinam a qualidade dos frutos, a idade da planta não influenciou na qualidade.
\end{abstract}

Palavras-chave: Bioma Cerrado, espécie nativa, fenofases, frutífera subtropical, Plinia

\begin{abstract}
Phenology, productivity and quality of jabuticabeiras fruits of different plant ages. Despite the increase in the demand for native fruits, little has been explored regarding the behavior of the species in the main producing regions. The objective of this study was to describe the phenology, productivity and fruit quality of 18 and 32 year-old jabuticaba trees propagated by seed in the municipality of Hidrolândia, GO, the main producing region of the fruit in the Central-West Region. It was verified that the jabuticaba trees vegetative development occurs from November to August. Their reproductive period, when irrigated, occurs September to October, varying from 29 to 46 days, being influenced by the plant's age and by climatic factors. Regarding the reproductive phenophases and the productivity of the jabuticaba tree, the plants have variable reproduction periods, productivity, fruit size and pulp yield. As for the factors that determine the quality of the fruits, the age of the plant did not influence the quality.
\end{abstract}

Key-words: Cerrado biome, native species, phenophases, subtropical fruit, Plinia

\section{INTRODUÇÃO}

A jabuticaba, pertencente ao gênero Plinia, é uma fruta nativa da Mata Atlântica, da família Myrtaceae, facilmente encontrada em quintais espalhados no Centro-Sul do Brasil (Ochse et al. 1966) e geralmente consorciada com outras frutíferas (Gomes 1983). Da mesma forma, a produção comercial estende-se por todo o Centro-Sul e embora em desenvolvimento, é pequena e limitada a determinadas regiões. Desta produção, aproximadamente $40 \%$ é comercializada na CEAGESP em São Paulo (Danner 2014). Em 2012, a comercialização de jabuticaba na CEAGESP foi de 2.231 toneladas, com um volume financeiro de R\$ 19.516.565 (Watanabe \& Oliveira, 2014).

Os fatores ambientais determinam os fenômenos biológicos, por isso são diretamente relacionados à fenologia. Os mecanismos que regulam esses fenômenos repetitivos ainda requerem bastante estudo, entretanto
Rathcke \& Lacey (1985) afirmam que os fatores climáticos, edáficos e bióticos determinam os períodos de floração e frutificação em plantas tropicais. Afirmam ainda que o fator climático é o de maior influência às fenofases, floração e frutificação, com destaque para oscilação das precipitações.

A jabuticabeira é uma espécie tipicamente de regiões de clima subtropical, toleram geadas de curta duração e podem suportar temperaturas de até $-3^{\circ} \mathrm{C}$. Porém, também é cultivada em clima tropical, desde que haja um período com temperaturas amenas (Phillips \& Goldweber 1978, Andersen \& Andersen 1988). A temperatura ótima para seu desenvolvimento é de $20^{\circ} \mathrm{C}$ a $25^{\circ} \mathrm{C}$, e temperaturas muito baixas podem afetar sua produtividade (Mattos 1983). A espécie tolera curto período de falta d'água e necessita de volumes de precipitação variando de 1200 a $1500 \mathrm{~mm}$ ano $^{-1}$, com chuvas regularmente distribuídas ao longo do ano e, no mínimo, $100 \mathrm{~mm}$ mensais (Mattos 1983). 
Observa-se que o início e a duração de cada etapa de desenvolvimento das plantas de jabuticabeira estão relacionados às condições ambientais, podendo essas ser alteradas conforme a ocorrência de fenômenos climáticos ou mesmo de origem antrópica, como a irrigação. (Lorenzi 2002, De'carli \& Spolidoro 2010). Neste sentido, Daronch et al. (2012) estudaram a fenologia e propriedades físicoquímicas de frutos de jabuticabeira nas condições do Planalto Médio riograndense e verificaram que o início da floração dos diferentes genótipos ocorreu no final de agosto e início de setembro. O final da floração se deu ainda no mês de setembro, e a duração do período de florescimento foi variável entre as cultivares (12 a 17 dias). O início da colheita se concentrou em meados de outubro, entre 10/10 a 17/10, encerrando no final de outubro e início de novembro. A duração da colheita variou, entre os genótipos, de 15 a 17 dias.

A colheita dos frutos ocorre de 1-1,5 meses após a florada (Donadio 2000) e é realizada nos meses de julho e agosto e de novembro e dezembro, com os frutos amadurecendo entre os meses de agosto e setembro, principal época, e de janeiro e fevereiro. A primeira produção, quando a planta é obtida por sementes, inicia após 8 a 12 anos (Suguino et al. 2012). Após o florescimento, a fixação de frutos varia de $7 \%$ a $30 \%$. O fruto da jabuticabeira necessita de 20 a 35 dias após o florescimento para poder amadurecer completamente (Manica 2000).

O fruto da jabuticabeira é do tipo baga, subgloboso, negro quando maduro, 1,6 a 2,2 cm de diâmetro, e liso, variando de 1 a 4 sementes por frutos, a casca é frágil e fina, e a polpa e um pouco ácida, mas com ótimo sabor (Wiltbank et al. 1983). Para Benza (1980) os frutos atingem até $3,5 \mathrm{~cm}$ de diâmetro, com polpa branca e sementes ovais, variando até quatro sementes por fruto. Sasso (2009) verificou que o número médio de sementes por frutos pode variar de uma a quatro. Essas características implicam no potencial dos frutos para a industrialização, podendo ser transformados em diversos produtos, com boa aceitabilidade no mercado.

Apesar deste reconhecido potencial, a literatura é bastante limitada em número de referências a esta fruteira (Citadin et al. 2010). Em razão disso, surge a necessidade de se conhecer o comportamento da cultura diante do ambiente em que ela se encontra, por meio de pesquisas sobre a fenologia da espécie. Isto permitirá a execução eficiente dos tratos culturais e auxílio na tomada de decisões. Assim, o produtor poderá planejar o manejo da melhor forma, de tal modo que seja alcançada uma boa produtividade, com frutos de boa qualidade. Desta maneira, o presente trabalho teve como objetivo descrever a fenologia e produtividade de plantas, bem como a qualidade de frutos oriundos de jabuticabeiras de 18 e 32 anos, propagadas por semente.

\section{MATERIAL E MÉTODOS}

O experimento foi conduzido em área comercial, situada no distrito de Nova Fátima, município de Hidrolândia, Goiás, nos anos de 2015 e 2016. A área localiza-se nas coordenadas geográficas $16^{\circ} 55^{\prime} 32.35^{\prime \prime}$ Sul e 49²1'39.76" Oeste.

Segundo a classificação de Köppen, o clima de Hidrolândia caracteriza-se como tropical Aw (quente e semi-úmido, com estação seca bem definida nos meses de maio a outubro). A altitude média é de $814 \mathrm{~m}$, sendo a temperatura média anual de $22,8^{\circ} \mathrm{C}$ e pluviosidade média de $1.411 \mathrm{~mm}^{-a n o}{ }^{-1}$. Durante todo o período do experimento a precipitação total foi de $1.105 \mathrm{~mm}$, em 2015 e de 1.207 $\mathrm{mm}$, em 2016, e a temperatura média de $24,77^{\circ} \mathrm{C}$, em 2015 e de $24,37^{\circ} \mathrm{C}$, em 2016 (Fig. 1).

O local do experimento possui cerca de 10.000 jabuticabeiras da variedade 'Pingo de Mel' (Vilela et al. 2012), no espaçamento $3 \times 3 \mathrm{~m}$, propagadas via sementes, com plantas de 18 e 32 anos de idade. O solo da área foi amostrado de 00-0,20 m e os resultados encontram-se na Tab. 1.

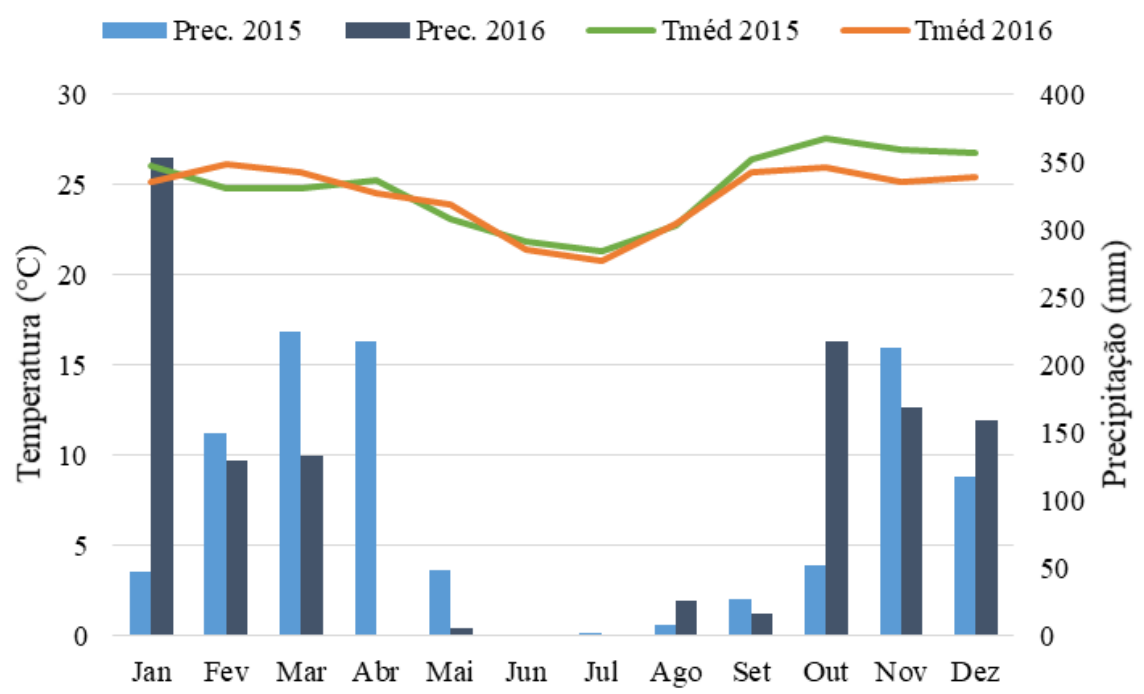

Fig. 1. Valores médios de temperatura $\left({ }^{\circ} \mathrm{C}\right)$ e precipitação $(\mathrm{mm})$ mensal em Hidrolândia, Goiás, nos anos de 2015 e 2016. 
Tabela 1. Análise de solo da área experimental de cultivo de jabuticabeiras.

\begin{tabular}{ccc}
\hline $\mathrm{pH}$ & & 4,51 \\
\hline $\mathrm{P}$ & $\mathrm{mg} \cdot \mathrm{dm}^{-3}$ & 1,87 \\
$\mathrm{~K}$ & & 28 \\
\hline $\mathrm{Ca}$ & $\mathrm{cmol}^{-3} \mathrm{dm}^{-3}$ & 1,70 \\
$\mathrm{Mg}$ & & 0,4 \\
$\mathrm{Al}$ & & 0,3 \\
$\mathrm{CTC}$ & & 5,17 \\
\hline $\mathrm{V}$ & & 41,99 \\
$\mathrm{M}$ & $\%$ & 12,14 \\
Argila & & 26 \\
Areia & & 18 \\
Silte & 56 \\
\hline
\end{tabular}

Foi fornecida água para as plantas uma vez por semana, por sulco, e esta se iniciou, em ambos os anos de avaliação, em julho e estendeu-se até outubro. Em cada uma das áreas, de 18 e 32 anos, foram selecionadas e identificadas, aleatoriamente, 10 plantas e marcados dois ramos de 20 $\mathrm{cm}$ por planta. A coleta de dados referente às fenofases vegetativas foi realizada quinzenalmente por um período de um ano. Já os dados referentes às reprodutivas foram coletados de três em três dias, durante dois períodos reprodutivos, 2015 e 2016.

As observações das fases fenológicas vegetativas realizaram-se durante o período de novembro de 2015 a outubro de 2016. Os dados foram registrados por meio de observações visuais. Nos eventos fenológicos foram observadas as fenofases: período de permanência das folhas verdes após a colheita (folhas jovens), ritidoma do caule e queda das folhas (período de repouso vegetativo).

No ano de 2015, para a avaliação do estádio fenológico reprodutivo, nas mesmas plantas, foram demarcados dois pontos de $20 \mathrm{~cm}$ do ramo no terço médio da planta, um de cada lado, e neles foram quantificadas gemas florais, flores em antese e frutos verdes. Os dados referentes ao estádio fenológico reprodutivo foram coletados a partir do dia 29 de agosto e a primeira avaliação ocorreu no dia 5 de setembro e a última no dia 3 de outubro do mesmo ano, até o amadurecimento do fruto. Para a avaliação do estádio fenológico vegetativo os resultados foram expressos registrando a descrição das mudanças observadas nas jabuticabeiras por planta, sendo "sim" para a presença da fenofase e "não" para a ausência, no decorrer das avaliações.

Determinou-se as percentagens de abscisão de flores, frutos imaturos e frutos maduros. Para estimar a abscisão de flores e frutos imaturos, fez-se a média aritmética dos dois pontos coletados de cada planta estabelecendo-se um valor, calculando-se a evolução de perda. Calculouse queda de frutos do ganho de massa até o fruto maduro pela diminuição do valor de início do ganho de massa do fruto pela quantidade de frutos maduros, multiplicando-se pelo valor de fruto maduro, e por último dividindo-se os valores por 100 .
No ano de 2016, a coleta de dados das fenofases reprodutivas realizou-se durante o período de agosto a outubro de 2016, totalizando três meses de observações. A coleta de dados iniciou-se no dia 17/08/2016 e terminou no dia $05 / 10 / 2016$, quando se encerrou a safra na região. Os dados foram registrados por meio de 12 observações visuais.

Nos eventos fenológicos reprodutivos foram quantificadas e observadas as fenofases: gemas florais, antese (flor aberta), fruto verde e fruto maduro. Considerouse o início da contagem quando a planta tinha, na sua maioria, a fenofase observada. Ao final dos experimentos, as plantas monitoradas foram caracterizadas biometricamente quantificando assim o número de ramos primários por planta (ramos da base da planta) e a altura da planta. No estádio fenológico reprodutivo foram quantificados os dados em todas as fases fenológicas desde o início da antese até o fruto maduro, e os dados foram submetidos à análise estatística descritiva, calculando-se as médias aritméticas de cada planta.

Em ambos os anos de avaliação, os frutos maduros foram colhidos em sua totalidade na porção demarcada do ramo, e levados ao laboratório com o intuito de caracterizálos biométrica e qualitativamente. Assim quantificou-se o número e a massa de sementes, massa de fruto, massa de casca, massa de sementes (depois de secas e separadas da polpa), diâmetros equatorial e polar dos frutos, acidez titulável, teor de sólidos solúveis, conforme a AOAC (2010), e ratio. A produtividade por planta foi determinada por meio da colheita de todos os frutos de cada árvore e levadas a uma balança para a averiguação da massa.

Para as análises laboratoriais foram utilizados balança digital para a pesagem dos frutos, sementes e casca. Utilizou-se também paquímetro digital para realizar a caracterização biométrica do fruto (diâmetros equatorial e polar). Para a avaliação de sólidos solúveis foi utilizado um refratômetro. A metodologia usada para determinar a acidez titulável foi do MAPA (BRASIL 1986).

Os dados foram submetidos à análise descritiva. Também foi feita correlação entre alguns parâmetros analisados.

\section{RESULTADOS E DISCUSSÃO}

Os resultados referentes ao estudo fenológico são posteriores ao término do período reprodutivo das safras 2015 e 2016. As plantas iniciaram mudanças, após o período reprodutivo, no seu estádio vegetativo, apresentando folhas novas recém-brotadas, observadas na primeira quinzena de dezembro, dois meses após a colheita.

Verificou-se no início das observações, em dezembro, o desprendimento da casca (ritidoma), fenômeno que foi se intensificando até fevereiro e que é característica marcante da família Myrtaceae. Foekel (1999) afirma que, na planta adulta, estas camadas de casca mais externas tornam-se velhas, morrem e se desprendem. 
Observou-se, no período chuvoso, que as folhas se mantiveram com tom mais verde, a partir de outubro, permanecendo assim até abril (Figs. 2A e 2B). A partir de maio, com a ocorrência do período mais frio, iniciouse a abscisão foliar concomitante com o surgimento das primeiras gemas florais sobre o caule. No mês de junho as plantas estavam praticamente desfolhadas, com aspecto de secas (Fig. 2C).

A queda das folhas no início de maio ocorreu simultaneamente com a redução da temperatura e o aumento do déficit hídrico no solo na região. Com o início da estiagem, a jabuticabeira entra em repouso, de três meses, para iniciar o período reprodutivo na estação chuvosa seguinte. Porém, houve fornecimento de água por sulcos, interrompendo este processo fisiológico da planta. Fator que também foi decisivo para a concentração do florescimento num período menor.

No período de repouso da planta, ocorre redução do desenvolvimento vegetativo, e as reservas acumuladas serão consumidas posteriormente, no período de florescimento, para o desenvolvimento das estruturas reprodutivas. A quantidade e a qualidade das reservas influenciam a fertilidade das gemas florais (Rosa et al. 2014). Indicações de que a intensidade do florescimento é dependente do conteúdo de carboidratos e de compostos nitrogenados na folha foram verificadas por Lovatt et al. (1988), os quais constataram o aumento desses elementos em condições em que a árvore é submetida a estresse hídrico.

Cruz et al. (2007), estudando plantas de citros, registraram a influência do déficit hídrico no florescimento das espécies, verificando que o estímulo para a emissão floral é dado durante o período de déficit. Assim, os autores relacionam o déficit à retomada do desenvolvimento das gemas nas plantas após o repouso vegetativo.

No ano de 2015, o período reprodutivo da cultura iniciou na primeira quinzena de setembro. Uma semana antes iniciou-se o fornecimento de água (29 de agosto). $\mathrm{Na}$ avaliação quantitativa de gemas florais, flores e frutos durante a fase reprodutiva, verificou-se que inicialmente as plantas apresentaram as gemas florais férteis e as que foram posteriormente abortadas (Tab. 2 e Fig. 3A).
Na primeira avaliação (início da fase reprodutiva), aos oito dias após a primeira irrigação, o número de gemas florais variou de 80 a 130 na área avaliada, aumentando até a segunda avaliação. Após 10 dias do aparecimento das gemas florais, observou-se a antese das flores, fase na qual ocorreu uma abcisão considerável de flores, característica natural da espécie (Tab. 2 e Figs. 3B, 3C).

A jabuticabeira necessita de temperaturas baixas para florescer, com ocorrência de não florescimento em caso de temperaturas elevadas durante o período em que inicia a fase de repouso das plantas, conforme observaram Miotto et al. (2013), no estado do Paraná, entre os meses de abril a maio. Porém, após queda brusca de temperaturas, observouse a produção de botões florais na última semana de julho e na primeira quinzena de agosto, flores na antese cinco dias após e formação dos frutos cinco dias posteriormente à abertura das flores.

$\mathrm{Na}$ fase de aparecimento dos chumbinhos (frutos pequenos verdes), 14 dias após a antese, evidenciou-se uma menor fixação de flores para ganho de massa dos frutos, culminando em uma média de 60 frutos por ramo. Estes se desenvolveram e após seis dias houve o ganho de massa do fruto, porém ainda verdes. Na última avaliação (18 dias após o florescimento), no dia 03 de outubro, colheram-se os frutos maduros definindo assim um ciclo reprodutivo de 29 dias (Tab. 2, Fig. 4). Magalhães (1991) destaca, em seu trabalho, que quando em sequeiro, o tempo de maturação da jabuticaba ocorreu aos 50-54 dias após o florescimento. Salienta-se que o fornecimento de água é importante para a antecipação do ciclo e melhor fixação dos frutos. Alttman (2019) afirma que o regime de irrigação diária proporciona maior produção de jabuticabas por planta, sem alterar suas características e o teor de substâncias de reservas nos ramos.

Após sete dias do ponto de colheita, os frutos maduros começam a cair, portanto, mesmo em condições climáticas adequadas, seu período de fixação na planta é bastante curto. Magalhães (1991) explica que isso ocorre em função da intensa atividade respiratória do fruto. Além disso, há o aumento do nível de antocianina, sugerindo o início do processo de senescência dos frutos de jabuticaba.

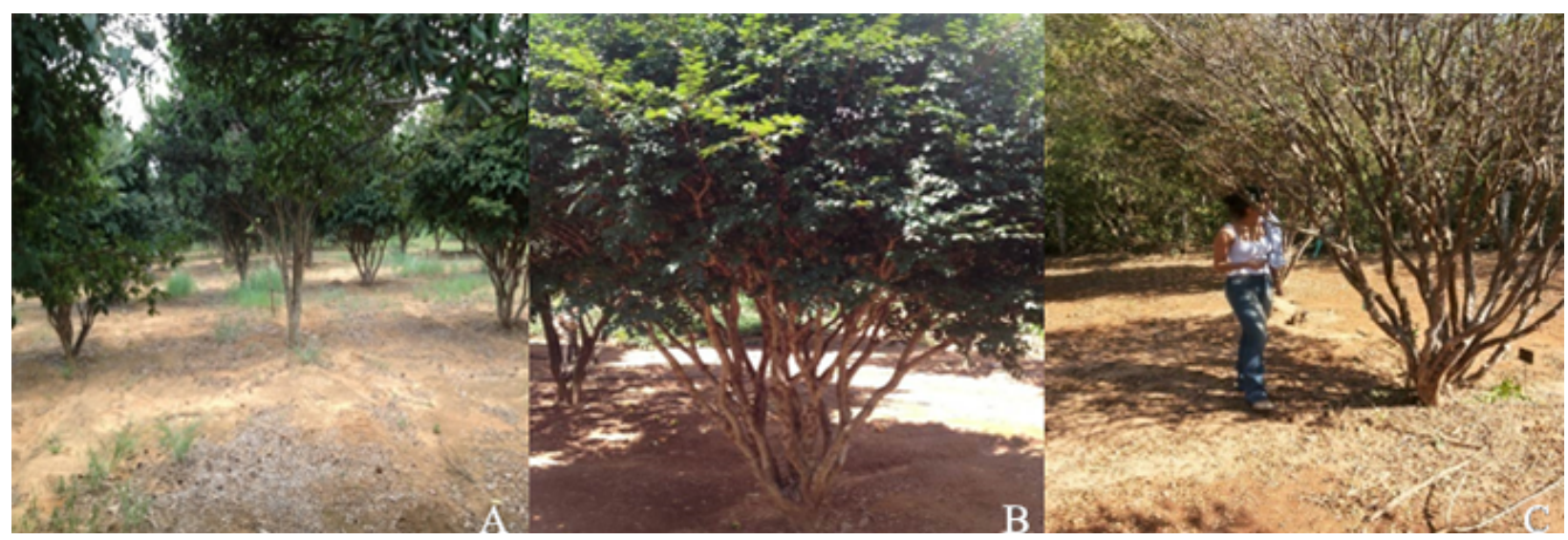

Figs. 2. A-C. A. plantas com tom verde escuro, durante o período chuvoso; B. plantas com folhas maduras; C. plantas com $90 \%$ de desfolha, antes do início do período de irrigação (safra 2015). 
Tabela 2. Valores médios de gemas florais, flores abertas, frutos fixados (verdes e maduros) e percentual de fixação de frutos de jabuticabeira (safra 2015). DP = Desvio padrão.

\begin{tabular}{|c|c|c|c|c|c|c|c|c|c|c|}
\hline \multirow{3}{*}{ Plantas } & \multicolumn{3}{|c|}{ Gemas florais } & \multicolumn{2}{|c|}{ Flores } & \multicolumn{5}{|c|}{ Frutos fixados } \\
\hline & \multirow{2}{*}{$05 /$ set } & \multirow{2}{*}{$09 /$ set } & \multirow{2}{*}{12 -set } & \multirow{2}{*}{15 -set } & \multirow{2}{*}{$19 /$ set } & \multirow{2}{*}{$\begin{array}{c}23 / \text { set } \\
\text { verdes }\end{array}$} & \multirow{2}{*}{$\begin{array}{c}26 / \text { set } \\
\text { verdes }\end{array}$} & \multirow{2}{*}{$\begin{array}{c}\text { 30/set } \\
\text { verdes }\end{array}$} & \multicolumn{2}{|l|}{ 03/out } \\
\hline & & & & & & & & & maduros & Fixação (\%) \\
\hline 1 & 81 & 97 & 95 & 216 & 209 & 43 & 30 & 22 & 18 & 41,86 \\
\hline 2 & 92 & 113 & 113 & 158 & 234 & 22 & 16 & 13 & 13 & 59,09 \\
\hline 3 & 74 & 111 & 110 & 79 & 163 & 64 & 52 & 29 & 27 & 42,19 \\
\hline 4 & 87 & 116 & 115 & 165 & 97 & 43 & 34 & 22 & 19 & 44,19 \\
\hline 5 & 100 & 142 & 140 & 208 & 103 & 44 & 37 & 23 & 20 & 45,45 \\
\hline 6 & 94 & 83 & 75 & 102 & 94 & 20 & 16 & 12 & 10 & 50,00 \\
\hline 7 & 99 & 181 & 175 & 266 & 171 & 100 & 37 & 19 & 16 & 16,00 \\
\hline 8 & 129 & 158 & 119 & 185 & 178 & 79 & 48 & 30 & 26 & 32,91 \\
\hline 9 & 122 & 124 & 106 & 193 & 191 & 21 & 20 & 13 & 10 & 47,62 \\
\hline 10 & 87 & 114 & 100 & 130 & 126 & 42 & 27 & 22 & 15 & 35,72 \\
\hline Média & 96,15 & 123,61 & 114,65 & 170,05 & 156,35 & 47,75 & 31,45 & 20,35 & 17,25 & 41,50 \\
\hline $\mathrm{DP}$ & 17.26 & 28.93 & 27.07 & 55.94 & 49.30 & 26.28 & 12.45 & 6.36 & 5.82 & 7.54 \\
\hline
\end{tabular}

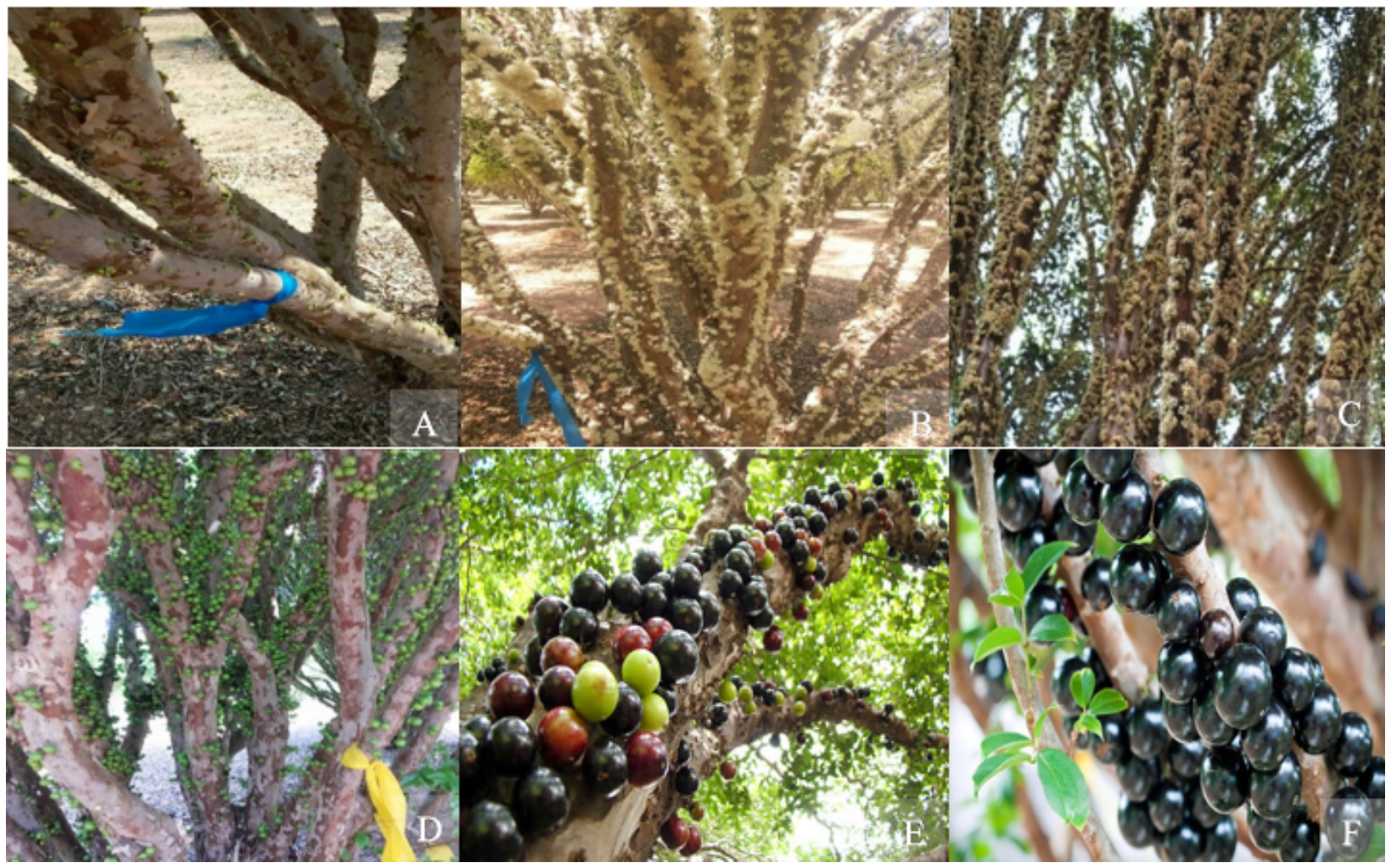

Figs. 3. A-F. Segunda avaliação do estágio reprodutivo; A. Gemas florais com 12 dias de período reprodutivo; B. Início do florescimento; C. Final da polinização e início do ganho de massa dos frutos; D. frutos verdes; E. frutos verdes e em fase de ganho de massa; F. frutos maduros (safra 2016).

Verificou-se uma queda significativa de frutos a partir do ganho de massa até o completo amadurecimento, com média de $50 \%$ de abscisão nesse período (Fig. 5). Esta queda dos frutos é comum na jabuticabeira, pois o número de flores que são abertas é muito grande e a polinização não é de $100 \%$. O percentual médio de fixação de frutos foi de 41,50\%, sendo maior que os dados de Duarte (1995), que afirma, após o florescimento a fixação varia de 7 \% a
$30 \%$. Desta maneira, acredita-se que o fornecimento de água tenha influência sobre a fixação de frutos.

O período do florescimento até a colheita da jabuticabeira foi de 19 dias (Fig. 6), período semelhante ao apresentado por Duarte (1995), entre 26 e 30 dias. E por Manica (2000), que registrou que os frutos levam de 25 a 35 dias após o florescimento para amadurecerem completamente, dependendo das condições edafoclimáticas atuantes neste período. 


\begin{tabular}{|l|c|c|c|c|c|}
\hline \multicolumn{5}{|c|}{ Ciclo reprodutivo da jabuticabeira de 18 anos (dia) } \\
\hline Etapas do ciclo & $1^{\circ}$ & $10^{\circ}$ & $14^{\circ}$ & $18^{\circ}$ & $29^{\circ}$ \\
\hline Eclosão das gemas florais & & & & & \\
\hline Florescimento & & & & & \\
\hline Fixação (frutos chumbinhos) & & & & & \\
\hline Ganho de massa (frutos verdes) & & & & & \\
\hline Fruto maduro & & & & & \\
\hline
\end{tabular}

Fig. 4. Ciclo fenológico reprodutivo de jabuticabeira (safra 2015).

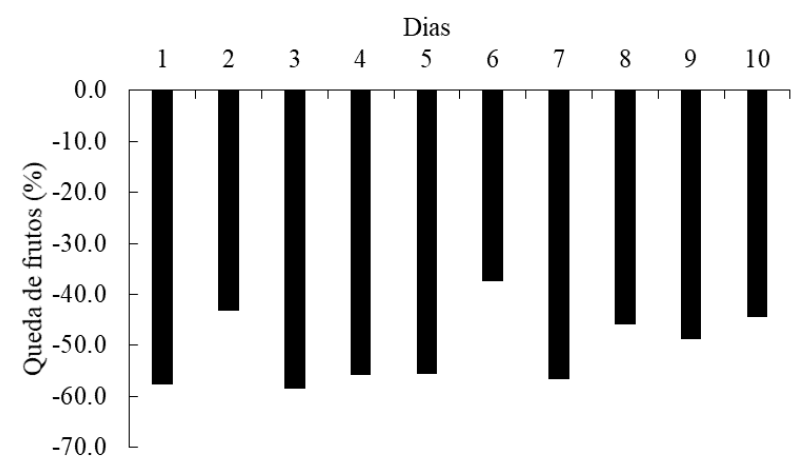

Fig. 5. Percentagem de queda de frutos de jabuticaba/planta, do início ao final do amadurecimento (safra 2015).

O período mais crítico da jabuticabeira, na região do estudo, é a queda das folhas até o início das chuvas, sendo que qualquer alteração no clima ou precipitação pluviométrica pode modificar o comportamento fisiológico da planta, podendo abortar ou iniciar o período reprodutivo precocemente, perdendo as flores e consequentemente provocando queda da produção. Segundo Corsato et al. (2005), o estudo da fenologia fornece ao produtor conhecimento sobre as prováveis datas de colheita.

Na região estudada, a irrigação das jabuticabeiras pode ser iniciada gradativamente no aparecimento das gemas florais para que o produtor escalone a frutificação, controle o ciclo fenológico e amplie o período de colheita

No estádio fenológico reprodutivo, a fixação para início do ganho de massa dos frutos é crítico, considerando a interferência dos fatores abióticos, os quais são limitantes para uma boa produção da jabuticabeira. Se o clima não for favorável, pode haver a perda de quase $100 \%$ da produção. Para as condições de cultivo apresentadas neste estudo, o estádio fenológico reprodutivo ocorreu no período de agosto a setembro (Fig. 7).

Na safra de 2016, o ciclo fenológico reprodutivo da jabuticabeira completou-se em 37 dias para as plantas com 18 anos, e 46 dias para as jabuticabeiras com 32 anos (Fig. 8). Valores similares aos obtidos para a cultura no estado do Rio Grande do Sul, em que se verificou a maturação dos frutos cerca de 38 dias após a plena floração (Altmann et al. 2019), principalmente na presença de água proveniente da irrigação.

Para as plantas de 32 anos observou-se que, em média, 517 flores abriram, totalizando um número estimado de 2.586 flores $\mathrm{m}^{-1}$ de ramo e apenas $11,9 \%$ dos frutos finalizaram seu ciclo, chegando à maturação final. Já nas plantas com 18 anos, em média, 267,2 flores abriram, totalizando 1.336 flores $\mathrm{m}^{-1}$ de ramo, com apenas $16,9 \%$ dos frutos finalizaram seu ciclo (Tab. 3). A pesquisa de Duarte et al. (1997) mostrou que o número de flores variou de $170 \mathrm{e}$ 1.500 por metro e os frutos, de 30 a 400 por metro de ramo, reafirmando que o número de flores é bastante superior ao número de frutos. Ribeiro (1991) estudou a fenologia de algumas espécies do Cerrado e caracterizou o padrão de frutificação da cagaiteira (Stenocalyx dysentericus (DC.) O. Berg.), também pertencendo à família Myrtaceae, como curto, com o fruto não permanecendo na planta por mais de 14 a 16 semanas, apesar da frutificação abundante.

Isso ocorre devido ao abortamento de grande parte das flores. Esse comportamento é natural da espécie, sendo que outros fatores podem influenciar neste processo, tais como a falta de água, ocorrência de vento, chuva e fatores antrópicos. Essa queda ocorre devido à sensibilidade das flores da jabuticabeira. Estudos realizados por Proença \& Gibbs (1994) sobre a biologia reprodutiva de algumas mirtáceas mostram que estas seguem um padrão de floração denominado "big bang", o que significa que a árvore tem uma floração muito intensa por um período relativamente curto de tempo.

Foi verificado que plantas de 18 anos produziram cerca de $44,29 \%$ a mais de gemas florais, quando comparadas às plantas de 32 anos. Porém, para as variáveis de quantidade de flores abertas e frutos maduros, houve superioridade das plantas de 32 anos, cerca de $48,34 \%$ e $41,84 \%$, respectivamente (Tab. 3).

Verificou-se que plantas jovens tiveram produtividade $61,57 \%$ menor, quando comparadas às plantas de 32 anos (Tab. 4). Considerando-se que o espaçamento é de $3 \mathrm{~m} \mathrm{x}$ $3 \mathrm{~m}$, a produtividade por hectare das plantas de 32 anos foi de 55,3 toneladas e das de 18 anos, de 21,3 toneladas. Quanto à altura das plantas, aquelas com 32 anos são mais altas, comparadas às de 18 anos, cerca de $28,43 \%$. 


\begin{tabular}{|c|c|c|c|c|c|c|c|c|c|c|c|c|}
\hline Evento & JAN & FEV & MAR & $\mathrm{ABR}$ & MAI & $\pi U N$ & $\pi U$ & $\mathrm{AGO}$ & SET & OUT & NOV & DEZ \\
\hline Vegetação & & & & & & & & & & & & \\
\hline $\begin{array}{l}\text { Desprendimento } \\
\text { da casca }\end{array}$ & & & & & & & & & & & & \\
\hline Queda das folhas & & & & & & & & & & & & \\
\hline
\end{tabular}

Fig. 6. Ciclo do estádio fenológico vegetativo de jabuticabeira (safra 2015).

\begin{tabular}{|c|c|c|c|c|c|c|c|c|c|c|c|c|}
\hline Evento & JAN & FEV & MAR & $\mathrm{ABR}$ & MAI & JUN & JUL & AGO & SET & OUT & NOV & DEZ \\
\hline Floração & & & & & & & & & & & & \\
\hline Frutificaçã & & & & & & & & & & & & \\
\hline Colheita & & & & & & & & & & & & \\
\hline
\end{tabular}

Fig. 7. Ciclo do estádio fenológico reprodutivo de jabuticabeira irrigada (safra 2015).

\begin{tabular}{|l|l|l|l|l|l|}
\hline \multicolumn{5}{|c|}{ Ciclo reprodutivo de jabuticabeira irrigada (dia) } \\
\hline \multicolumn{1}{|c|}{ Etapas do ciclo (18 anos) } & $1^{\circ}$ & $6^{\circ}$ & $20^{\circ}$ & $26^{\circ}$ & $37^{\circ}$ \\
\hline Eclosão das gemas florais & & & & & \\
\hline Florescimento & & & & & \\
\hline Fixação (frutos chumbinhos) & & & & & \\
\hline Ganho de massa (frutos verdes) & & & & & \\
\hline Fruto maduro & $1^{\circ}$ & $13^{\circ}$ & $26^{\circ}$ & $35^{\circ}$ & $46^{\circ}$ \\
\hline \multicolumn{1}{|c|}{ Etapas do ciclo (32 anos) } & & & & & \\
\hline Eclosão das gemas florais & & & & & \\
\hline Florescimento & & & & & \\
\hline Fixação (frutos chumbinhos) & & & & & \\
\hline Ganho de massa (frutos verdes) & & & & & \\
\hline Fruto maduro & & & & & \\
\hline
\end{tabular}

Fig. 8. Ciclo fenológico reprodutivo de jabuticabeira, com 18 e 32 anos, cultivada em Hidrolândia, Goiás (safra 2016).

Com relação às análises físico-químicas dos frutos, verificou-se que, de maneira geral a massa dos frutos, da casca e da semente, assim como o rendimento de polpa é maior em plantas mais jovens (Tab. 5). Isso se deve ao menor número de frutos por planta, diminuindo a competição pelos recursos, tais como fotoassimilados. Também estudando a cultura da jabuticabeira, Zerbielli et al. (2016) observaram que a massa de frutos variou de 6,4 $\mathrm{g}$ a $11,4 \mathrm{~g}$, o número de sementes fruto ${ }^{-1}$ entre $1,0 \mathrm{e} 1,7 \mathrm{e}$ o rendimento de polpa, de $57,8 \%$ a $76,1 \%$.
O baixo número de sementes e a massa das sementes são características extremamente importantes para o consumo in natura e para a utilização no processamento industrial, pois aumentam o rendimento. A variedade 'Pingo de mel' tem como característica, menor tamanho de frutos, quando comparada com outras variedades, como observado por Zerbielli et al. (2016) que ao avaliarem 40 genótipos obtiveram massas de frutos variando de $6,4 \mathrm{a}$ $11,4 \mathrm{~g}$, justificando os dados. 
Tabela 3. Valores médios de gema floral, flor aberta e fruto maduro e percentual de fruto maduro de jabuticabeiras de diferentes idades (safra 2016).

\begin{tabular}{ccccc}
\hline Idade & Gema floral & Flor aberta & Fruto maduro & $\%$ de fruto \\
\hline 32 anos & 99,5 & 517,2 & 49,0 & 9,47 \\
18 anos & 178,6 & 267,2 & 28,5 & 10,67 \\
Média & 139,05 & 392,2 & 38,7 & 9,87 \\
DP & 84,71 & 239,49 & 16,37 & 10,56 \\
\hline
\end{tabular}

DP - Desvio padrão.

Tabela 4. Valores médios de produtividade, altura e número de ramos primários de jabuticabeiras de diferentes idades (safra 2016).

\begin{tabular}{cccc}
\hline Idade & Produtividade $\left(\mathrm{kg}_{\text {planta }}{ }^{-1}\right)$ & Altura $(\mathrm{m})$ & Número de ramos primários \\
\hline 32 anos & 49,8 & 5,03 & 6,00 \\
18 anos & 19,14 & 3,60 & 6,40 \\
Média & 34,47 & 4,33 & 6,20 \\
DP & 22,64 & 0,88 & 1,57 \\
\hline
\end{tabular}

DP - Desvio padrão.

Tabela 5. Valores médios de massa de fruto, massa de casca, massa de sementes, rendimento de polpa e número de sementes de jabuticabas, com idades diferentes (safra 2016).

\begin{tabular}{cccccc}
\hline Idade & Massa de fruto $(\mathrm{g})$ & Massa de casca $(\mathrm{g})$ & Massa de sementes $(\mathrm{g})$ & Rendimento de polpa (\%) $^{\text {Número de sementes fruto }^{-1}}$ \\
\hline 32 anos & 5,09 & 1,70 & 1,83 & 30,65 & 2,30 \\
18 anos & 6,67 & 1,92 & 1,93 & 42,28 & 1,89 \\
Média & 5,88 & 1,81 & 1,88 & 36,46 & 2,10 \\
DP & 1,37 & 0,25 & 0,61 & 9,48 & 0,34 \\
\hline
\end{tabular}

DP - Desvio padrão.

Para as características físico-químicas, observou-se pouca variação entre as plantas de diferentes idades em relação ao diâmetro equatorial, ao diâmetro polar e à relação entre estes. No entanto, em relação às plantas mais velhas, plantas jovens produziram frutos com teores de sólidos solúveis $4,87 \%$ maiores, acidez titulável $26,26 \%$ menor e, consequentemente, maior ratio (Tab. 6).

Zerbielli et al. (2016), estudaram a diversidade físicoquímica dos frutos de jabuticabeira e encontraram valores de diâmetro equatorial e polar dos frutos variando entre 21,6 $\mathrm{mm}$ a $26,0 \mathrm{~mm}$, e de $21,7 \mathrm{~mm}$ a $26,5 \mathrm{~mm}$, respectivamente, valores de sólidos solúveis, variando entre $10,8^{\circ} \mathrm{Brix}$ e $15,8^{\circ}$ Brix, acidez titulável em baixas porcentagens, não ultrapassando $0,59 \%$ de ácido cítrico. Os dados de Zerbielli et al. (2016), referentes ao ratio, foram bastante superiores aos encontrados, já esperado, pois a acidez titulável teve valores bem inferiores. A média de ratio foi de 6,5 , valor próximo ao que o MAPA estabelece para o suco de laranja, que deve ser maior ou igual a 7,00 (Figueira et al. 2010), indicando que a fruta é bastante adequada para a industrialização.

As alterações fisiológicas que comandam as diferentes etapas de desenvolvimento da jabuticabeira, estão intrinsecamente ligadas aos fatores climáticos que às circundam. No entanto, com a utilização das técnicas de manejo, tais como irrigação e adubação, também podem resultar em respostas variáveis por parte dos vegetais (Lorenzi 2002, De'carli \& Spolidoro 2010).

A jabuticabeira é uma frutífera de importância comercial e com potencial exploração frente às tendências de alimentação saudável, podendo ser utilizada como alimento funcional. No entanto, para que o cultivo se torne atrativo ao produtor é necessário o desenvolvimento de pesquisas visando à geração de informações sobre o comportamento da espécie. Também em relação à fisiologia da espécie, faltam informações atuais, mesmo que a jabuticabeira ocorra em grande parte do território nacional, em diferentes ambientes.

Para as condições observadas no presente estudo, o desenvolvimento vegetativo da jabuticabeira ocorre no período de novembro a agosto; o reprodutivo, desde que irrigado, de setembro a outubro e varia de 29 a 46 dias, sendo influenciado pela idade da planta e por fatores climáticos.

Em relação às fenofases reprodutivas e a produtividade da jabuticabeira, as plantas apresentam períodos de reprodução, produtividade, tamanho de frutos e rendimento de polpa variáveis. Em complemento, quanto aos fatores que determinam a qualidade dos frutos, a idade da planta não tem influência sobre a mesma. 
Tabela 6. Valores médios de diâmetro equatorial e polar do fruto, relação diâmetro equatorial/diâmetro polar, sólidos solúveis totais, acidez titulável e ratio de jabuticabas, com diferentes idades (safra 2016).

\begin{tabular}{|c|c|c|c|c|c|c|}
\hline Idade das plantas & $\mathrm{DE}(\mathrm{mm})$ & DPo (mm) & Relação DE/DPo & Sólidos solúveis ( ${ }^{\circ}$ Brix) & Acidez titulável $^{1}$ & Ratio \\
\hline 32 anos & 17,24 & 17,15 & 1,00 & 13,97 & 2,50 & 5,60 \\
\hline 18 anos & 17,05 & 16,92 & 1,00 & 14,65 & 1,98 & 7,40 \\
\hline Média & 17,14 & 17,03 & 1,00 & 14,31 & 2,24 & 6,50 \\
\hline DP & 1,82 & 1,38 & 0,08 & 1,33 & 2,01 & 0,55 \\
\hline
\end{tabular}

DE - diâmetro equatorial; DPo - diâmetro polar; DP - Desvio padrão. ${ }^{1}$ gramas de ácido cítrico por $100 \mathrm{~g}$ de polpa.

\section{REFERÊNCIAS}

Altmann, T., Heisler, G., da Silva, L.F. \& Souza, P.V.D. 2019. Desenvolvimento e maturação de frutos de jabuticabeira (Plinia peruviana) na região da Depressão Central do Estado do Rio Grande do Sul, Brasil. Pesquisa Agropecuária Gaúcha 25(1/2):32-43.

Andersen, O. \& Andersen, V.U. 1988. As frutas silvestres brasileiras. Globo, Rio de Janeiro. 203p.

Association Official Analytical Chemists - AOAC. 2010. Official Methods of Analysis of AOAC International. 18. ed. Gaithersburg.

Benza, J.C. 1980. Frutales Nativos. Universidade Nacional Agrária La Molina, Peru. 366p

BRASIL. Ministério da Agricultura. Portaria $\mathrm{n}^{\circ} 76$ de 26 de novembro de 1986. Dispõe sobre os métodos analíticos de bebidas e vinagre. Diário Oficial da República Federativa do Brasil, Brasília, 28 nov. 1986. Seção 1, p. 2.

Citadin, I., Danner, M.A. \& Sasso, S.A.Z. 2010. Jabuticabeiras. Revista Brasileira de Fruticultura 32(2):343-344.

Corsato, C.E., Scarpare Filho, J.A. \& Verdial, M.F. 2005. Phenology of persimmon tree 'Rama Forte' in tropical climate. Bragantia 64(3):323-329.

Cruz, M.D.C.M.D., Rocha, R.H.C., Siqueira, D.L.D. \& Salomão, L.C.C. 2007. Avaliação do potencial hídrico foliar, umidade do solo e temperatura do ar no período pré-florescimento dos citros. Ciência e Agrotecnologia 3(5):1291-1296.

Danner, M. Potencial de cultivo da jabuticabeira no Paraná. In Anais do II Simpósio Paranaense de Fruticultura. Disponível em: https:// docplayer.com.br/15674596-Potencial-de-cultivo-da-jabuticabeirano-parana-1.html. Acessado em 19.06.2020.

Daronch, T., Zerbielli, L., Malfatti, C.E. \& Nienow, A.A. 2012. Fenologia e propriedades físico-químicas de frutos de jabuticabeira nas condições do Planalto Médio, RS. In Anais da XXII Mostra de Iniciação Científica (C. R. Schons, ed), Universidade do Passo Fundo: Passo Fundo, p. 4-5.

Donadio, L.C. 2000. Jabuticaba (Myrciaria jaboticaba (Vell.) Berg). Jaboticabal: Funep, 55p.

De'Carli, G.A.L. \& Spolidoro, M.L.C.V. 2010. Estudo fenológico de Myrtaceae (Myrciaria cauliflora) no museu Casa da Hera/Vassouras - RJ; In Anais do I Simpósio de Pesquisa em Mata Atlântica (W. C. Rodrigues, ed), p. 110-112.

Duarte, O. 1995. Vermehrung, Bluten - und fruchtentwicklung sowie lagerung Von jaboticaba (Myrciaria cauliflora (Mart.) Berg). Berlin, $105 \mathrm{p}$.

Duarte, O., Huete, M. \& Ludders, P. 1997. Propagation of jaboticaba (Myrciaria cauliflora (Mart.) Berg) by terminal leafy cuttings. Acta Horticulturae 32(3):123-128.

Figueira, R., Nogueira, A.M.P., Venturini Filho, W.G., Ducatti, C., Queiroz, É.C. \& Pereira, A.G.D.S. 2010. Análise físico-química e legalidades em bebidas de laranja. Alimentos e Nutrição Araraquara 21(2):267-272.

Foekel, C. 1999. Casca da árvore do eucalipto: aspectos morfológicos, fisiológicos, florestais, ecológicos e industriais visando a produção de celulose e papel. Eucalyptus Online Book \& Newsletter. 109p.
Gomes, R.P. 1983. Fruticultura Brasileira. Nobel, São Paulo. 446p.

Lorenzi, H. 2002. Árvores Brasileiras. Manual de identificação e cultivo de plantas arbóreas nativas do Brasil. Plantarum Ltda, São Paulo. 384p.

Lovatt, C., Zheng, Y. \& Hake, K.D. 1988. A new look at the KraussKraybill hypothesis and flowering in citrus. In Annals of International Citrus Congress, Tel Aviv, Israel. Proceeding. p. 475-483.

Magalhães, M.M. 1991. Desenvolvimento e carboidratos constituintes do fruto de jaboticaba (Myrciaria jaboticaba Berg cv. 'Sabará'). Dissertação 77f., Universidade Federal de Viçosa, Viçosa.

Manica, I. 2000. Frutas exótica, nativas e silvestres, 1: Técnicas de produção e mercado: abiu, amora-preta, araçá, bacuri, biribá, carambola, cereja-do-rio-grande; jabuticaba. Cinco Continentes, Porto Alegre. 327p.

Mattos, J.R. 1983. Fruteiras nativas do Brasil: jaboticabeiras. Nobel, Porto Alegre. 92p.

Miotto, R., Schainhuk, L., Vigolo, J. \& Betemps, D.L. 2013. Identificação de acessos e padrões fenológicos de jabuticabeiras presente na área urbana da cidade de Laranjeiras do Sul/PR. In Anais do III Seminário de Ensino, Pesquisa e Extensão da UFFS (SEPE, ed), Universidade Federal da Fronteira Sul, Laranjeiras do Sul, p. 1-2.

Ochse, J.J., Soule Jr, M.J., Dijkman, M.J. \& Wehlburg, C. 1966. Tropical and Aubtropical Agriculture. The Macmillan Company, New York.

Phillips, R.L. \& Goldweber, S. 1978. The jaboticaba. [S.1.]. Horticulture Science Departament. 2 p. (Document FC-39)

Proença, C.E.B. \& Gibbs, P.E. 1994. Reproductive biology of eight sympatric Myrtaceae from Central Brazil. New Phytologist 126:343354.

Rathcke, B. \& Lacey, E.P. 1985. Phenological patterns of terrestrial plants. Review of Ecology and Systematics 16:179-214.

Ribeiro, J.F. 1991. Fenologia de espécies lenhosas do Cerrado. In Anais do Encontro de Botânicos do Centro-Oeste. UNB, Brasília. p. 40

Rosa, A.M., Pescador, R., Brighenti, A.F. \& Brunetto, G. 2014. Fertilidade e reservas de carbono e nitrogênio em gemas de ramos das viníferas 'Cabernet Sauvignon'e 'Nebbiolo'. Revista Brasileira de Fruticultura 36(3):576-584.

Sasso, S. A. Z. 2009. Propagação vegetativa de jabuticabeira. Dissertação 64f., Universidade Tecnológica Federal do Paraná, Pato Branco.

Suguino, E., Martins, A.N., Turco, P.H.N., Cividanes, T.M.S. \& Faria, A.M. 2012. A cultura da jabuticabeira. Pesquisa e Tecnologia 9(1):1-7.

Vilela, R.C.F., Assis, J.G.D.A., Nóbrega Filho, L. \& Viana, B.F. 2012. Sistema reprodutivo e diversidade genética de quatro espécies de Myrciaria (Myrtaceae, jabuticabeiras). Acta Botanica Brasilica 26(4):727-734.

Watanabe, H.S. \& Oliveira, S.L. 2014. Comercialização de frutas exóticas. Revista Brasileira de Fruticultura 36(1):23-38.

Wiltbank, M.V., Chalfun, N.N.J. \& Andersen, O. 1983. The jaboticaba in Brazil. Proceedings of the Americans Society for Horticultural Science 27: 57-69.

Zerbielli, L., Nienow, A., Dalacorte, L., Jacobs, R. \& Daronch, T. 2016. Diversidade físico-química dos frutos de jabuticabeiras em um sítio de ocorrência natural. Revista Brasileira de Fruticultura 38(1): 107-116. 